\title{
The effect of providing resuscitation training to front- line staff on rates of maternal and trauma mortality in two health districts in Malawi
}

\section{Tom Schnittger ${ }^{1}$, Paul Downie ${ }^{1}$, Gregor}

\section{Pollach $^{2}$}

1.College of Anaesthetists of Ireland

2.Department of Anaesthesia, College of Medicine,University of

Malawi, Blantyre, Malawi

\section{Background and Goals}

Malawi has one of the highest maternal mortality rates in the world, between $807^{1}$ to $1120^{2}$ maternal deaths per 100,000 live births, per year. Only $31 \%$ of children born to mothers who die in the peri-partum period survive infancy ${ }^{3}$. It is Malawian government policy to actively encourage women to deliver in either health centres or hospitals with a skilled attendant. However a considerable number of women still deliver in villages with no skilled attendant.

Malawi, in common with much of Africa, also has a very high Road Traffic Accident fatality rate at 26 deaths per 100,000 inhabitants per year; the comparable figure for The Netherlands is 4.1. ${ }^{4}$

A district hospital usually only has 1-2 doctors on staff, a health centre none. Care is provided by nurse midwives or medical assistants (three years training) or clinical officers (four years training). The three day High Dependency, Obstetrics and Trauma management (HOT) training program evolved over a number of years to provide knowledge and skills to first responders at health centre and district hospital level. The course focuses on effective management of women with obstetric emergencies and also trauma patients, especially road traffic accident (RTA) victims. The course has been run sixteen times since 2005 and a total of 391 health care workers have successfully completed training. We set out to evaluate whether this training has impacted on care and maternal (MMR) and trauma (TMR) mortality rates.

Table 1 Basic Statistics addresses general resuscitation principles as well as specific problems that had been identified as important in Malawian healthcare. Service delivery issues which were identified as particular problems in Malawi were also addressed. These included issues such as the safe effective transfer of a sick patient; problems with poor communication; teamworking and effective use of the skills and resources that were available in a resource- poor setting.

\section{Material and Methods}

The course was modeled on some of the courses that already exist in other countries. The MOET (Managing Obstetric Emergencies and Trauma) and ALSO (Advanced Life Support in Obstetrics) courses were considered to most closely approach the needs that had been identified in Malawi. In addition to the management of obstetric emergencies and trauma however it was also considered important to emphasise the importance of high dependency care, to maximize survival of patients who had been successfully resuscitated. A 210 page course manual was devised, based on other resuscitation course manuals but revised and rewritten to reflect local needs and practices. This manual was printed locally and distributed to course delegates three weeks before the commencement of the course, to allow adequate time for them to read it. The delegates were encouraged to use the manual throughout the course and to make notes in it, so that they became familiar with it and could use it later as a familiar reference text for emergencies.

The courses were of three days duration. This is a duration that is used in other countries and has been found to be optimal in terms of concentration and learning by the delegates.

\begin{tabular}{|l|l|l|l|l|l|l|l|}
\hline & $\begin{array}{l}\text { Number } \\
\text { of courses } \\
\text { held }\end{array}$ & $\begin{array}{l}\text { Doctors } \\
\text { trained }\end{array}$ & $\begin{array}{l}\text { Midwives } \\
\text { /nurses } \\
\text { trained }\end{array}$ & $\begin{array}{l}\text { Clinical Of- } \\
\text { ficers } \\
\text { trained }\end{array}$ & $\begin{array}{l}\text { Medical As- } \\
\text { sistants } \\
\text { Trained }\end{array}$ & $\begin{array}{l}\text { Instruc- } \\
\text { tor } \\
\text { potential } \\
\text { identi- } \\
\text { fied }\end{array}$ & $\begin{array}{l}\text { Total } \\
\text { Del- } \\
\text { egates } \\
\text { trained }\end{array}$ \\
\hline $2005-07$ & 4 & 3 & 21 & 69 & 0 & 12 & 93 \\
\hline 2009 & 3 & 3 & 38 & 21 & 14 & 11 & 76 \\
\hline 2010 & 9 & 3 & 125 & 57 & 37 & 21 & 222 \\
\hline Totals & $\mathbf{1 6}$ & $\mathbf{9}$ & $\mathbf{1 8 4}$ & $\mathbf{1 4 7}$ & $\mathbf{5 1}$ & $\mathbf{4 4}$ & $\mathbf{3 9 1}$ \\
\hline
\end{tabular}

The Blantyre district and two non-urban health districts, Thyolo and Chiradzulu were initially targeted. Consultation with District Health Officers in these areas confirmed that there were high maternal mortality and RTA mortality in their districts, and that training aimed at helping staff to manage these problems would be appreciated.

As resuscitation protocols for the management of common obstetric emergencies such as haemorrhage and eclampsia have a lot in common with general resuscitation protocols for trauma, a short training program was developed that
The courses were organized so that either the first or the last day was on a weekend day, to minimize the disruption that taking so many delegates out of a district would have. The teaching faculty consisted mainly of Malawian instructors, who were medical anaesthesia trainees (MMeds), non-medical Anaesthesia Clinical Officers, and midwives and intensive care nurses. There were also 2-3 medical anaesthetists from the Irish College of Anaesthetists on the faculty; the Irish College together with Irish Aid funded the courses.The course material consisted of a combination of lectures, small 
practical resuscitation skills were first demonstrated and then each delegate learned and completed the skill.This was felt to be very important for the practical management of an emergency, as theoretical knowledge is of no use if it cannot be translated into practical intervention. The skills that were taught, and that each delegate successfully completed to graduate from the course are described in Table 2. The lecture topics are described in Table 3, and the small group discussion topics are in Table 4. In addition the faculty roleplayed several emergency situations for the delegates, such as cases of severe multiple trauma and obstetric emergencies; and demonstrated correct management including logical diagnosis, teamwork, allocation of specific tasks, constant re-evaluation and the importance of follow-on high quality care.

Table 2 - Practial skills taught on the HOT course

\begin{tabular}{|l|}
\hline Insertion of a chest drain on a fresh goat cadaver model \\
\hline Airway management using oropharyngeal airways and bag-mask-valve devices on a mannequin \\
\hline Cardio Pulmonary Resuscitation (CPR) including chest compression on a mannequin \\
\hline Technique of cervical stabilization, spine immobilization and log rolling \\
\hline Technique for safe vaginal breech delivery taught on a mannequin pelvis \\
\hline Techniques for safe management of shoulder dystocia, taught on a mannequin pelvis \\
\hline Neonatal resuscitation including airway management and CPR taught on a neonatal mannequin \\
\hline
\end{tabular}

Table 3-Lecture topics delivered on the HOT course

\begin{tabular}{|l|}
\hline The structured approach to all emergencies \\
\hline Triage of multiple emergencies \\
\hline How to effect the safe transfer of a patient \\
\hline Evaluation and management of shock \\
\hline Management of head injuries \\
\hline Massive Obstetric haemorrhage \\
\hline Management of pre-eclampsia and eclampsia \\
\hline
\end{tabular}

Table 4-Small group discussion topics on the HOT course

\begin{tabular}{|l|}
\hline Sepsis \\
\hline Eclampsia \\
\hline Haemorrhage \\
\hline High Dependency Unit care \\
\hline Common complications of anaesthesia \\
\hline Placental abruption \\
\hline
\end{tabular}

Delegates were then invited to practice a number of resuscitation scenarios in teams of two, and were subsequently marked on a standard resuscitation test scenario. A 50 question MCQ was also administered at the end of the course to test acquisition of theoretical knowledge.

Of the 391 delegates who had completed the course by November 2010386 passed initially and the other 5 passed after some supplementary instruction. A total of 44 instructor potential candidates were identified; most of these were invited to observe on later courses; and several later

Maternal mortality rate (MMR) is an internationally recognized measure of basic obstetric care, and allows for between country comparisons, and for monitoring improvements in care provision within an area. There is no equivalent internationally recognised Trauma mortality rate. Rates may be quoted as fatalities per head of population, per kilometer of road, per number of vehicles or other such indices. For the purposes of this paper we have defined the Trauma Mortality Rate (TMR) as the number of in-hospital deaths after a road traffic accident, per 1000 admissions for road traffic accidents, per year. We have chosen this formula as the raw data that was available to us was the number of Road Traffic Accident (RTA) cases admitted per year, and the number of RTA in-patient deaths per year. Obviously RTA deaths that occur before admission are missed, as are RTA cases that are not deemed sufficiently serious to warrant inpatient care. However we felt this TMR index could be used as a useful marker of the quality of trauma care delivered by the health care staff. became full instructors on further courses.

During the period in question a number of changes occurred in the Malawian healthcare system, general healthcare spending increased, and there were improvements introduced in malaria and HIV care. There were also some specific improvements in obstetric care - notably provision of basic obstetric equipment for vacuum extraction in some health centres, and other more obstetric based basic skills training. In order to establish whether the reductions seen in maternal mortality in Thyolo and Chiradzulu could be attributed to the 


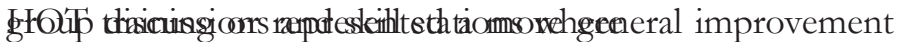
in care we looked at comparable data from a health district where no HOT training had occurred. Machinga health district was chosen as it is also in the southern region of Malawi. Data was collected for each health district for the years 2005 to 2009, and for the first 9 months of 2010. This data was routinely collected by monthly enquiry by the inhouse Hospital Management Information Systems (HMIS) in each hospital. This data is routinely collected for the health ministry and we acknowledge the help of the HMIS staff in giving us access to this data.

\section{Results and Discussion}

Numbers of maternal deaths, and numbers of live births with a skilled attendant present (i.e. in a health centre or district hospital) are shown in table 5 , together with a computation of the MMR. This data is depicted graphically in Graph 1. The reduction in MMR seen in all health districts is all the more significant when one considers that the number of births that occurred in a health centre or district hospital increased by more than $50 \%$ in each district reviewed over the years in question.

Similar data for RTA trauma is shown in table 6 and displayed in graph 2.

Table 5-number of live births and MMR for the three health districts 2005-2010

\begin{tabular}{|c|c|c|c|c|c|c|c|c|c|}
\hline & $\begin{array}{l}\text { Thyolo } \\
\text { District }\end{array}$ & & & $\begin{array}{l}\text { Chirad zulu } \\
\text { District }\end{array}$ & & & $\begin{array}{l}\text { Machinga } \\
\text { District }\end{array}$ & & \\
\hline & $\begin{array}{l}\text { Live } \\
\text { births }\end{array}$ & $\begin{array}{l}\text { Maternal } \\
\text { deaths }\end{array}$ & MMR & Live births & $\begin{array}{l}\text { Maternal } \\
\text { deaths }\end{array}$ & MMR & $\begin{array}{l}\text { Live } \\
\text { births }\end{array}$ & $\begin{array}{l}\text { Maternal } \\
\text { deaths }\end{array}$ & MMR \\
\hline 2005 & 9,313 & 14 & 150 & 6,406 & 15 & 235 & 11053 & 36 & 326 \\
\hline 2006 & 9,758 & 10 & 102 & 6,640 & 24 & 370 & 10934 & 31 & 284 \\
\hline 2007 & 11,028 & 10 & 91 & 8,167 & 15 & 180 & 12179 & 30 & 246 \\
\hline 2008 & 13,763 & 7 & 51 & 8,767 & 9 & 101 & 15266 & 25 & 164 \\
\hline 2009 & 15,830 & 9 & 57 & 9,088 & 8 & 89 & 17441 & 22 & 126 \\
\hline 2010 (1:9mo) & 8,181 & 5 & 55 & 7,977 & 6 & 76 & 17337 & 17 & 98 \\
\hline
\end{tabular}

Table 6-number RTA admissions and TMR for the three health districts 2005-2010

\begin{tabular}{|l|l|l|l|l|l|l|l|l|l|}
\hline & $\begin{array}{l}\text { Thyolo } \\
\text { RTA } \\
\text { admissions }\end{array}$ & $\begin{array}{l}\text { RTA } \\
\text { deaths }\end{array}$ & TMR & $\begin{array}{l}\text { RTA } \\
\text { admissions }\end{array}$ & $\begin{array}{l}\text { RTA } \\
\text { deaths }\end{array}$ & TMR & $\begin{array}{l}\text { RTA } \\
\text { admissions }\end{array}$ & $\begin{array}{l}\text { RTA } \\
\text { deaths }\end{array}$ & TMR \\
\hline 2005 & 552 & 3 & 5.43 & 465 & 13 & 27.96 & 2170 & 7 & 3.2 \\
2006 & 564 & 4 & 7.09 & 536 & 3 & 5.58 & 1588 & 2 & 1.3 \\
\hline 2007 & 650 & 9 & 13.84 & 554 & 0 & 0 & 2220 & 1 & 0.5 \\
2008 & 594 & 13 & 21.88 & 580 & 7 & 12.07 & 1179 & 5 & 4.2 \\
\hline 2009 & 617 & 0 & 0 & 586 & 8 & 13.65 & 885 & 2 & 2.3 \\
$2010(1 * 9$ mo $)$ & 150 & 1 & 6.7 & 416 & 1 & 2.4 & 830 & 2 & 2.4 \\
\hline
\end{tabular}

Graph 1 - Maternal Mortality Rate (2010 data Jan-Sept only)

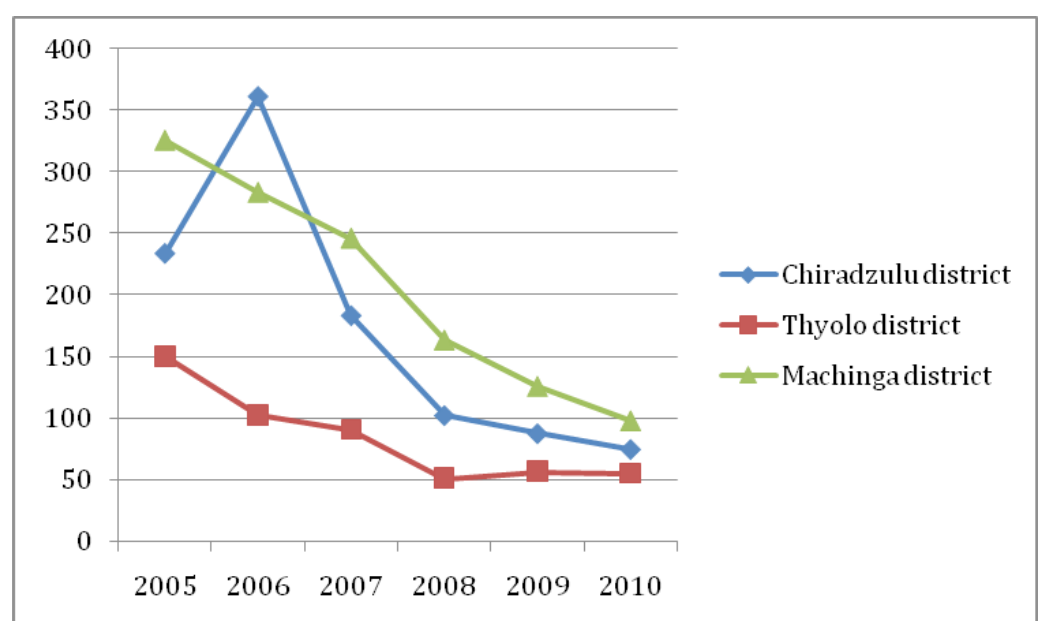


Graph 2 - Trauma Mortality Rate, deaths per 1000 RTA admissions

(2010 data Jan-Sept only)

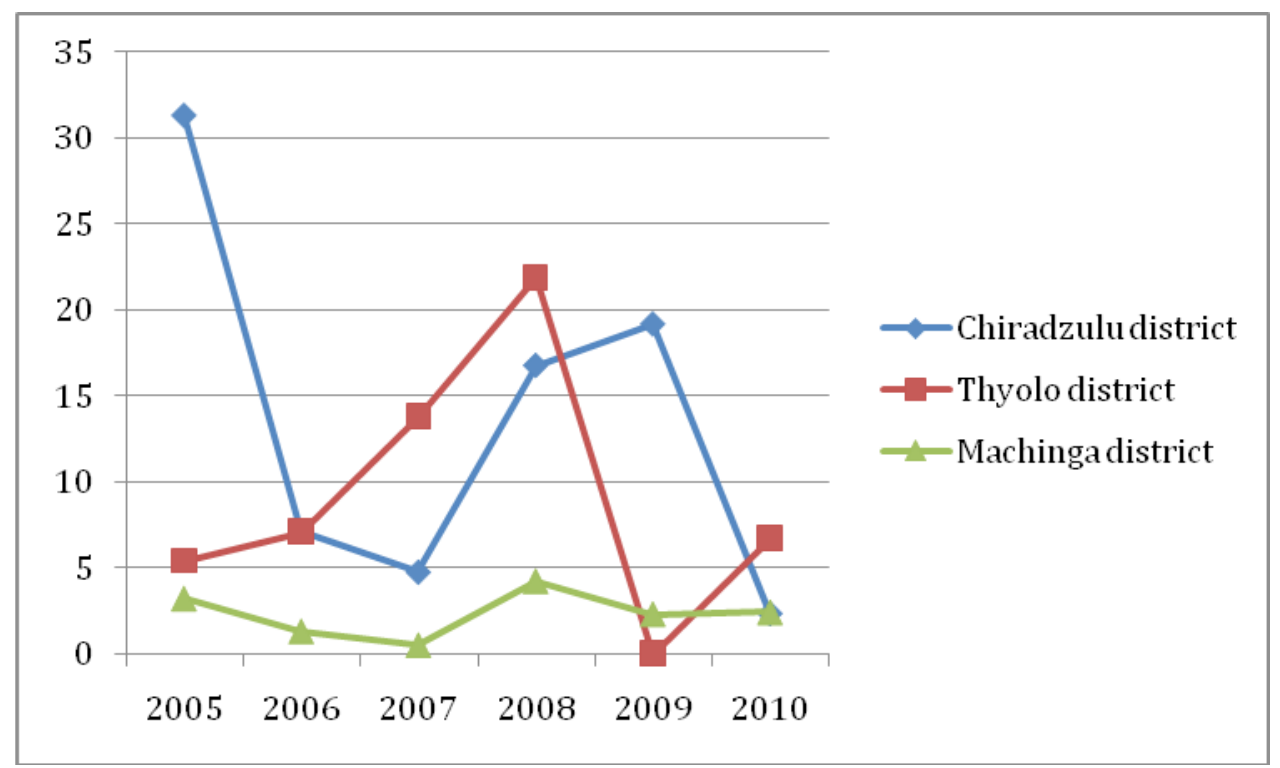

These figures show a steady reduction in maternal mortality over the years in question in all three health districts, however the maternal mortality for Machinga for the first nine months of 2010 is still nearly twice that of Thyolo and a third greater than that of Chiradzulu.

The trauma death rate for Machinga is fairly consistent, whereas the rate for Thyolo and Chiradzulu shows considerable variability from year to year. This may be because the number of trauma cases from these two districts was a lot smaller, so the death rate may be more vulnerable to episodic peaks in trauma occurrence.

The leading causes of maternal mortality in developing regions ${ }^{5}$ are haemorrhage (35\%) and hypertension(18\%), which together account for half of all deaths in expectant or new mothers. Indirect causes, including malaria, HIV/AIDS and heart disease, result in 18 per cent of maternal deaths. Other direct causes, such as obstructed labour, complications of anaesthesia or caesarean section, and ectopic pregnancy, lead to 11 per cent of all deaths during pregnancy or childbirth.
Complications of abortion and miscarriage account for $9 \%$, sepsis for $8 \%$ and embolism for $1 \%$ of deaths.

The vast majority of these deaths are avoidable. Haemorrhage, for example, which accounts for over one third of maternal deaths, can be prevented or managed through a range of interventions administered by a skilled health-care provider with adequate equipment and supplies at health centre or district hospital level. Delegates to the courses were asked to reflect on what barriers existed in their workplace to the delivery of optimal care to these patients. Some of their comments are included in Table 7. Discussion of these issues however sometimes revealed that appropriate equipment and drugs might exist in the hospital, but might not necessarily be in the most appropriate place, for example where emergency cases might be admitted. After the course many delegates indicated that they felt more confident in dealing with emergency cases, and felt better able to address issues of triage, communication and teamwork.

Table 7. - Barriers to effective care delivery - as described by course delegates

\begin{tabular}{|l|}
\hline Poor triage \\
\hline Poor communication between health workers \\
\hline Poor teamwork \\
\hline Lack of knowledge \\
\hline Lack of equipment, IV fluids and drugs \\
\hline Lack of a High Dependency Unit \\
\hline
\end{tabular}

A formal review of the efficacy of the course in empowering health care workers with resuscitation knowledge and skills was carried out by members of the Irish College of Anaesthetists in April $2010^{6}$. They visited the health districts and evaluated 32 health workers who had been trained on HOT courses. The evaluation consisted of a participant questionnaire, focused interview with the participants and case history reviews. Based on the questionnaire participants reported the following levels of satisfaction with these aspects of the courses:

Presentation $82 \%$; Content 88\%; Relevance 100\%; Teaching technique 84\%; Applicability 82\%

The participants reported improvements in practice in the following areas:

airway, trauma, obstetrics, eclampsia, haemorrhage and sepsis management; neonatal resuscitation; spinal stabilisation; mass casualty management; team work and organizational prioritization.

All participants also recorded improvements in their work practice both in obstetrics and trauma. These improvements were presented by way of case studies in the case of each participant. 


\section{Conclusion}

We conclude therefore that while there have been gratifying reductions in maternal mortality in all three health districts, HOT training may have played a role in reducing this rate further in Thyolo and Chiradzulu as the MMR in these districts is significantly less than that in Machinga.

We feel that it is too early to draw significant conclusions regarding the impact of HOT training on trauma mortality.

\section{References}

1 Statement delivered by the Honourable Mrs Bernadette Mlaka Maliro, MP at the UN during the 54th session of the commission on the status of women, March 3rd 2010

2 E Geubbels. Epidemiology of Maternal Mortality in Malawi. Malawi Medical Journal 2006; 18(4):206-225

3 McDermott JM, Slutsker L, Steketee RW et al. Prospective assessment of mortality among a cohort of pregnant women in rural Malawi. Am J Trop Med Hyg 1996;55:66-70

4 Peden, M., Scurfield, R., Sleet, D., Mohan, D., Hyder, A. A., Jarawan, E., Mathers, C. World Report on Traffic Injury Prevention, WHO 2004

5 The Millennium Development Goals Report 2010 United Nations

6 Irish College of Anaesthetists report on HOT courses 2010

\section{FIRST ANNOUNCEMENT: VIROLOGY AFRICA 2011}

WEBSITE: www.virology.cmc-uct.co.za

On behalf of the Institute of Infectious Disease and Molecular Medicine of the University of Cape Town and the Poliomyelitis Research Foundation, we are pleased to invite you to "Virology Africa 2011" at the Cape Town Waterfront.

VENUE AND DATES: This conference will take place at the UCT Graduate School of Business and the Breakwater Lodge, Victoria and Alfred Waterfront, Cape Town, from the evening of 29 November - 2 December 2011. This is a sophisticated venue inside a world-class tourist attraction, with spectacular views: see http://www.breakwaterlodge.co.za/ for more details! The venue has a limited capacity $(n=220)$, so early registration is advised.

Abstract deadline: 01st August 2011

"Early Bird" registration deadline: 01st September 2011. Final registration deadline: 15th October 2011 The ACADEMIC PROGRAMME will include plenary-type presentations from internationally recognised speakers. It is intended that the programme should cover the widest possible spectrum of virology in Africa. Topics will include (but will not be limited to) HIVIAIDS, vaccinology, emerging and special pathogens, veterinary virology, viral immunology, viral epidemiology, viruses and cancer, plant and insect and fungal viruses, and molecular mechanisms of pathogenesis. A specialist workshop on human papillomavirus is being planned. The venue will allow for parallel workshops of oral presentations and poster sessions. The preliminary programme will be posted on the webpage well in advance of the conference.

Senior students are encouraged to present their research. A limited number of bursaries will be available for students presenting at the conference. Application forms will be available on the webpage.

If you are prepared to fund an internationally recognised scientist to speak at the conference or if you wish to organise a specialist workshop as part of the conference, please contact:

Professor Anna-Lise Williamson at anna-lise.williamson@uct.ac.za or

Professor Ed Rybicki at ed.rybicki@gmail.com

SPONSORSHIPI TRADE EXHIBITION: We do hope you will be able to participate and have attached a booking form listing possible sponsorship opportunities. Please complete and return this form as soon as possible.

REGISTRATION: The registration and accommodation booking forms are on the webpage and attached. ENQUIRIES can be directed to the Conference Management Centre, UCT Faculty of Health Sciences:

Deidre Raubenheimer / Email: deidre.raubenheimer@uct.ac.za / Tel: 0214066167 or

Fatima Saban / Email: fatima.saban@uct.ac.za / Tel: 0214066330

We are looking forward to hearing from you.

Professor Anna-Lise Williamson \& Professor Ed Rybicki - Convenors, Virology Africa 2011 